\title{
Logboeken als middel om de kwaliteit van het medisch onderwijs te evalueren
}

\author{
H.M.J. Raghoebar-Krieger, W. Bender, H.G. Kreeftenberg, D.Th. Sleijfer
}

\section{Samenvatting}

Bij het vaststellen van onderwijskwaliteit gaat het om zichtbaar te maken wat studenten geleerd hebben (output). Omdat de output van het onderwijs wordt beïnloed door de input (leermiddelen, docenten, patiënten) en de wijze waarop studenten leren (cognitieve processen), zijn ook deze aspecten van belang om geëvalueerd te worden. In het Raamplan 1994 worden de eindtermen (o.a. ziektebeelden) voor de basisartsopleiding beschreven. Kennis over deze ziektebeelden wordt getoetst door middel van examens, maar omdat het kennisniveau afhankelijk is van ervaringen die studenten opdoen met patiënten die aan deze ziekten lijden, zijn patiëntcontacten essentieel. Medische faculteiten moeten hun studenten dus in de gelegenheid stellen ervaringen op te doen met de vereiste ziektebeelden. Het doel van dit onderzoek is de kwaliteit van het medisch onderwijs te beschrijven door (1) te bepalen of de ziektebeelden die het Raamplan als eindtermen formuleert aanwezig zijn in de praktijk en (2) te bepalen of studenten ervaringen opdoen met de vereiste ziektebeelden. Om deze vragen te beantwoorden is een logboek ontwikkeld. Artsen en studenten hebben in hun logboek de ziekten geregistreerd van patiënten waarmee zij geconfronteerd zijn op de afdeling Interne Geneeskunde. De ingevulde logboeken zijn geanalyseerd.

Het logboek is een goed instrument om het onderwijs te evalueren. De onderwijskwaliteit kan hiermee in termen van het Raamplan beschreven worden. Gebleken is dat het aanbod van ziektebeelden op de afdeling voldoende is om aan de eindtermen uit het Raamplan te voldoen, mits het co-schap doorlopen wordt op zowel een algemene als een specialistische onderafdeling. Studenten benutten de mogelijkheden die geboden worden op de afdeling om te leren echter onvoldoende.

\section{Inleiding}

De verantwoordelijkheid voor de kwaliteitszorg van het medisch onderwijs ligt bij de medische faculteiten. Door middel van interne en externe evaluaties wordt systematisch en structureel nagegaan of het onderwijs aan de gestelde criteria voldoet. ${ }^{1-3}$ Bij het evalueren van de kwaliteit van het eindproduct wordt bepaald wat studenten hebben geleerd (output). Deze vorm van evaluatie heeft betrekking op de mate waarin studenten competenties verwerven. De verworven competenties worden doorgaans gemeten op basis van drie aspecten, namelijk kennis, vaardigheden en gedrag, middels verschillende toetsvormen zoals verslagen, multiple-choice toetsen, mondeling examen en praktische klinische examens. Het percentage studenten dat slaagt voor de toetsen kan worden beschouwd als een maat voor de output van het onderwijs. Maar deze output wordt onder andere beïnvloed door de wijze waarop studenten leren.

Onderzoek naar leerprocessen van studenten hebben in de afgelopen jaren geleid tot cognitietheorieën die relevant zijn geweest voor de inrichting van medisch onderwijs. ${ }^{4}$ Een andere groep van variabelen die de output beïnvloedt is de 
'input', zoals docenten, colleges, patiënten en andere 'leermiddelen'. Evaluatie van deze variabelen vindt frequent binnen het medisch onderwijs plaats, zoals de evaluaties die de medische faculteiten uitvoeren in het kader van de interne kwaliteitszorg, ${ }^{2,5}$ maar ook zoals de jaarlijks uitgevoerde Elsevier enquête, ${ }^{6}$ en de landelijke visitatie van de VSNU. ${ }^{7}$ In het Raamplan 1994, 8 eindtermen van de artsopleiding, wordt een beschrijving gegeven van hetgeen van een arts aan het einde van de basisopleiding mag worden verwacht op het gebied van kennis, vaardigheden en attitude. Delen van het Raamplan zijn opgenomen in de wet BIG (Beroepen in de Individuele Gezondheidszorg). ${ }^{9}$ De eindtermen van het Raamplan zijn onderverdeeld in 'algemene eindtermen', 'problemen' en 'disciplinegebonden ziektebeelden en vaardigheden'.

De eindtermen van het Raamplan beschrijven in principe het product (output), maar impliceren hiermee ook eisen aan de input, omdat beide nauw met elkaar verbonden zijn. De kwaliteit van het onderwijs zal dus enerzijds vastgesteld kunnen worden door te beoordelen welke eindtermen de studenten hebben bereikt, maar anderzijds door vast te stellen welke inputvariabelen aanwezig zijn. In dit onderzoek zijn de eindtermen met betrekking tot de disciplinegebonden ziektebeelden onderwerp van studie geweest. Het niveau van kennis over ziektebeelden wordt getoetst door middel van verschillende toetsvormen. Echter, het te verwerven kennisniveau is afhankelijk van de mogelijkheden die studenten krijgen om kennis en ervaring op te doen met patiënten die aan deze ziektebeelden lijden. Patiëntcontacten zijn daarom essentieel, en de medische faculteiten zullen hun studenten dus in de gelegenheid moeten stellen om bijvoorbeeld tijdens de co-assis- tentschappen met deze ziektebeelden geconfronteerd te worden.

De centrale vraag van het onderzoek was: 'kan er inzicht worden verkregen in de omstandigheden (input) waarbinnen de eindtermen met betrekking tot de ziektebeelden worden bereikt?'. Om deze vraag te beantwoorden is de beschikbaarheid van patiënten (ziektebeelden) in de kliniek onderzocht; vervolgens is vastgesteld in welke mate studenten dit beschikbare patiëntenaanbod benutten. Om bovenstaande vragen te beantwoorden is een evaluatie-instrument (logboek) ontwikkeld. Het onderzoek is uitgevoerd binnen het co-schap Interne Geneeskunde van de Faculteit der Medische Wetenschappen aan de Rijksuniversiteit Groningen.

\section{Instrument}

De disciplinegebonden ziektebeelden uit het Raamplan die betrekking hebben op de Interne Geneeskunde zijn opgenomen in een logboek. ${ }^{10}$ Omdat het aantal van 231 ziektebeelden te veel is voor een co-assistentschap dat 12 weken duurt, is het aantal door clustering gereduceerd. Ziektebeelden met overeenkomstige symptomen en pathogenese zijn gegroepeerd en hiërarchisch gestructureerd in 3 niveaus. Het hoogste niveau is het cluster van orgaan gebonden ziektebeelden (bijvoorbeeld: ziekten van het maagdarmkanaal) en bestaat uit verschillende subclusters (bijvoorbeeld: oesophagusafwijkingen, maagafwijkingen). Elk subcluster bestaat uit een aantal ziektebeelden, het laagste niveau (bijvoorbeeld: achalasie, gastritis). Vervolgens zijn binnen elk subcluster op grond van incidentie, prevalentie en prototypisch karakter één of meer ziektebeelden benoemd die relevant zijn om te leren. Deze relevante ziektebeelden zijn in twee groepen te onderscheiden: een groep van 37 'essentiële' ziektebeelden die alle essentieel 
zijn om te leren, en een groep van 65 ziektebeelden die studenten ook moeten leren, maar die uit een grotere verzameling van 194 gekozen mogen worden (optioneel). Een voorbeeld: het subcluster maagafwijkingen bestaat uit 8 ziektebeelden. Eén van deze ziektebeelden ('gastritis') is benoemd als een 'essentieel' ziektebeeld vanwege zijn prototypisch karakter en vanwege de incidentie. Van de overige 7 ziektebeelden mogen 2 ziektebeelden willekeurig gekozen worden, en zijn dus optioneel. Aan de overige 5 ziektebeelden worden geen eisen gesteld. Door in het logboek aantekeningen te maken over de ziektebeelden waarmee de student in het co-schap geconfronteerd wordt, kan dit logboek fungeren als evaluatiemiddel.

\section{Materiaal en methode}

\section{Procedure}

Gegevens zijn verzameld op 5 van de 11 onderafdelingen van de afdeling Interne Geneeskunde, te weten: Algemene Interne Geneeskunde I, Algemene Interne Geneeskunde II, Nefrologie, Longziekten en Oncologie, die respectievelijk 12, 12, 32, 27 en 11 bedden omvatten. Co-schappen op de afdeling Interne Geneeskunde be- staan uit 2 perioden van 4 weken, waarbij de studenten willekeurig worden ingedeeld op een onderafdeling.

\section{Patiëntenaanbod}

Het aanbod van ziektebeelden is vastgesteld op de onderafdelingen Algemene Interne Geneeskunde I en II, Nefrologie, Longziekten en Oncologie. Artsen die fulltime werkzaam waren op deze afdelingen hebben in de periode van oktober 1998 tot en met mei 1999 ziektebeelden in het logboek geregistreerd. De reden om artsen de ziektebeelden te laten registreren in plaats van studenten, is gebaseerd op het gegeven dat niet alle studenten alle patiëntontmoetingen registreren, ${ }^{11-12}$ en dat er veel verschillen zijn tussen hun registraties. ${ }^{13}$ Gegevens van drie onderafdelingen (Algemene Interne Geneeskunde I en II, en Oncologie) werden verzameld gedurende een periode van 16 weken. Van de onderafdelingen Nefrologie en Longziekten besloeg de verzamelingsperiode respectievelijk 12 en 14 weken.

Aan de artsen is gevraagd om de aard van de ziektebeelden waarmee patiënten op de afdeling zijn opgenomen dagelijks in het logboek te registreren. Hierbij moesten alle ziektebeelden worden ver-

Tabel 1. Een voorbeeld uit het logboek, waarbij links de ziektebeelden staan aangegeven waarmee patiënten zich presenteren (de ziektebeelden met een * zijn de 'essentiële' ziektebeelden). Rechts staat de kolom 'patiëntenaanbod' waarin de arts invult of de patiënt met het betreffende ziektebeeld op de afdeling lag.

TRACTUS UROGENITALIS
Nieren: functiestoornissen
* acute nierinsufficiëntie
* chronische nierinsufficiëntie
* nephrotisch syndroom
cystische nieraandoeningen
renale osteodystrofie
Ontstekingen
* glomerulonephritis
interstitiële nefritis
et cetera.


meld per patiënt; niet alleen de eerste diagnose, maar ook alle neven diagnosen. Bijvoorbeeld, als een patiënt is opgenomen vanwege ijzergebreksanaemie, maar ook lijdt aan hypertensie en diabetes mellitus, dan werden deze drie ziektebeelden geregistreerd. In tabel 1 is een voorbeeld van een deel van het logboek opgenomen.

\section{Gebruik van patiëntenaanbod}

Om te bepalen in welke mate studenten gebruik maken van de ziektebeelden binnen het patiëntenaanbod, zijn de registraties door zowel artsen als studenten verzameld, en met elkaar vergeleken. Deze gegevensverzameling vond plaats in de periode van oktober 1998 tot en met februari 1999 (op de onderafdeling Nefrologie) en van maart 1999 tot en met mei 1999 (op de onderafdeling Longziekten).

De instructie die de arts kreeg hoe het logboek in te vullen, is identiek aan de invulinstructie zoals in het eerste deelonderzoek is beschreven. De instructie voor de studenten werd bij aanvang van het coschap gegeven; zij moesten alle patiënten met wie zij geconfronteerd worden in het logboek invullen. Net zoals bij de arts moest het invullen dagelijks gebeuren en moesten zij zowel hoofd- als nevendiagnose van de patiënt vermelden. Van de studenten werd verwacht dat zij bij alle patiënten een anamnese afnamen en een lichamelijk onderzoek verrichtten, en hun bevindingen in een status beschreven. Supervisie en feedback werden gegeven gedurende de dagelijkse visites en tijdens de wekelijkse discussie met de stafleden (grote visite). Zowel de student als de arts zag alle patiënten die zijn opgenomen op de onderafdeling, ook al had de student verschillende andere onderwijsverplichtingen buiten de onderafdeling. Het logboek voor studenten is ook identiek aan het logboek voor de artsen, alleen de kolom 'aanbod patiënten' in tabel 1 is voor de student een kolom waarin aangegeven wordt of hij/zij met de betreffende patiënt geconfronteerd is geweest. Eens per week werden de ingevulde logboeken van de arts en student opgehaald, gekopieerd en geretourneerd.

De geregistreerde ziektebeelden van de arts en student zijn alleen met elkaar vergeleken indien beiden in dezelfde week op dezelfde onderafdeling werkzaam zijn geweest. Zo konden de gegevens van 20 arts-student paren worden vergeleken. Om vast te stellen welke fouten studenten maken bij het registreren van ziektebeelden is de sensitiviteit en specificiteit bepaald. Bovendien zijn de registraties vergeleken van 4 student paren die gedurende dezelfde week op dezelfde onderafdeling het logboek hebben ingevuld.

\section{Analyse}

\section{Patiëntenaanbod}

Om te bepalen welke ziektebeelden er beschikbaar zijn gedurende een co-schap van 4 weken op een onderafdeling, zijn de verzamelde data van de 37 'essentiële' ziektebeelden en de 65 'optionele' ziektebeelden omgezet in een verwachte waarde (E).

De E-waarde (het verwachte aanbod van ziektebeelden uit een bepaald cluster gedurende een bepaalde periode) is in wezen een kansberekening. Een voorbeeld: als de arts in een periode van 4 weken een bepaald ziektebeeld observeert, dan is de kans dat dit ziektebeeld in één bepaalde week geobserveerd wordt ? en de kans dat het niet geobserveerd wordt ?. De kans die de student heeft om een patiënt met een bepaald ziektebeeld dus te zien is voor een periode van 4 weken: $\mathrm{P}=1-(1-\mathrm{p})^{4}$. In ons voorbeeld is de 
kans dus gelijk aan 1 minus de kans om het ziektebeeld niet te zien gedurende de 4 weken $(1-1 / 4)^{4}$, dus $\mathrm{P}=1-(1-1 / 4)^{4}$. Om de verwachte waarde van alle ziektebeelden binnen één cluster te berekenen, worden de verwachte waarden van elk ziektebeeld afzonderlijk bij elkaar opgeteld.

\section{Gebruik patiëntenaanbod}

Om vast te stellen of de student gebruik maakt van de beschikbare ziektebeelden is de betrouwbaarheid van de registraties door de student bepaald door de registratie van student en arts (standaard) te vergelijken en uit te drukken in een overeenstemmingscoëfficiënt, sensitiviteit en specificiteit. Van zowel het totaal aantal ziektebeelden (231) als de groep van 'essentiële' ziektebeelden (37) zijn de registraties van arts en student in een kruistabel (tabel 2) met elkaar vergeleken.
De Jaccard (J) coëfficiënt is gebruikt om de overeenstemming te meten. ${ }^{14}$ In deze coëfficiënt wordt het aantal correct positieven gedeeld door de som van het aantal correct positieven, de vals positieven en de vals negatieven. De ziektebeelden die noch door arts noch door student werden gezien, werden niet in de berekening meegenomen. De reden hiervoor lag in het feit dat het totaal aantal ziektebeelden in het logboek (231) te hoog lag om in een week geobserveerd te worden. Daarnaast speelt het argument een rol dat het logboek gegevens bevat van de leerervaringen van de student met bepaalde ziektebeelden; het is daarom relevanter iets te weten over de betrouwbaarheid van ervaringen met ziektebeelden die aanwezig zijn op de afdeling, dan met ziektebeelden die niet aanwezig zijn. Deze argumenten leiden tot de keuze van de $\mathrm{J}$ coëfficiënt in plaats van de veel gebruikte Kappa coëfficiënt.

Tabel 2. Overeenstemming van observaties door arts en student van ziektebeelden (37/231).

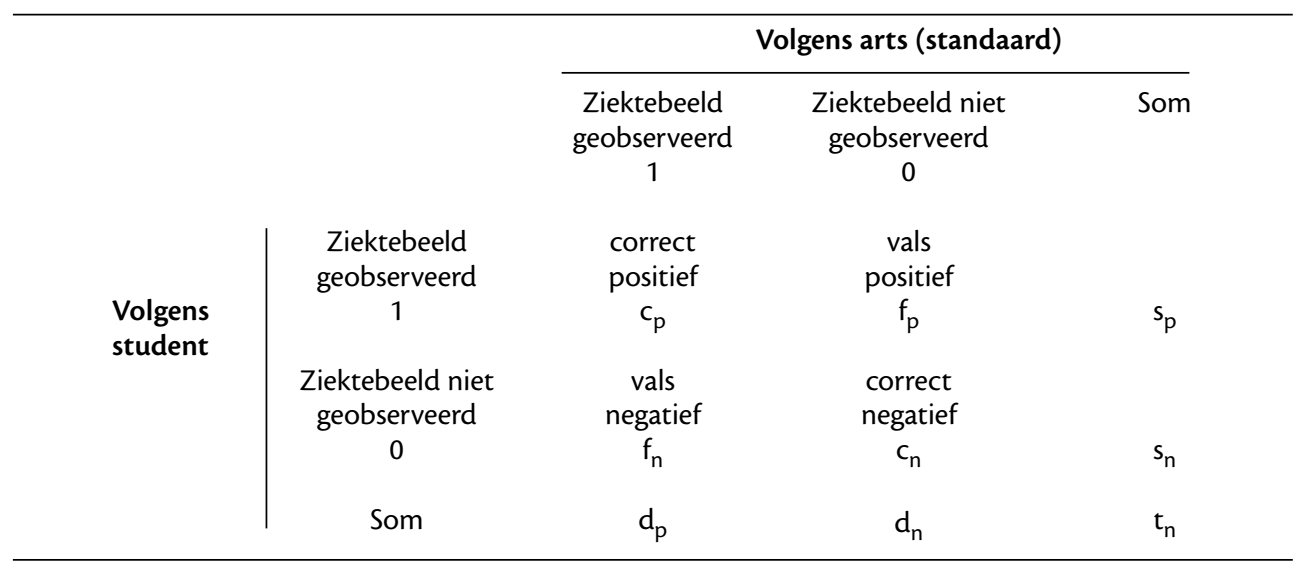

\footnotetext{
$c_{\mathrm{p}}$ : aantal ziektebeelden geobserveerd door zowel arts als student.

$f_{p}$ : aantal ziektebeelden geobserveerd door student, maar niet door arts.

$s_{\mathrm{p}}$ : aantal ziektebeelden geobserveerd door student.

$f_{n}$ : aantal ziektebeelden niet geobserveerd door student, maar wel door arts.

$c_{n}$ : aantal ziektebeelden niet geobserveerd door student, noch door arts.

$\mathrm{s}_{\mathrm{n}}$ : aantal ziektebeelden niet geobserveerd door de student.

$d_{p}$ : aantal ziektebeelden geobserveerd door arts.

$\mathrm{d}_{\mathrm{n}}$ : aantal ziektebeelden niet geobserveerd door arts.

$t_{n}$ : totaal aantal ziektebeelden.
} 
Sensitiviteit en specificiteit werden berekend om het aantal vals negatieve en het aantal vals positieve registraties vast te stellen. Het aantal vals negatieven is gelijk aan 1 minus de sensitiviteit; het aantal vals positieve is gelijk aan 1 minus de specificiteit. Sensitiviteit is het aantal ziektebeelden dat geobserveerd is door de arts en door de student, en wordt berekend door de correct positieven te delen door de som van de correct positieven en de vals negatieven. Specificiteit verwijst naar het aantal ziektebeelden dat niet door de dokter en wel door de student wordt geregistreerd. Specificiteit wordt berekend door de correct negatieven te delen door de som van correct negatieven en vals positieven.

Om inzicht te krijgen in de verschillen tussen de logboek registraties van studenten onderling, is ook de overeenstemming (J) berekend voor 4 paren studenten die gedurende dezelfde week op dezelfde onderafdeling hun co-schap liepen.

\section{Resultaten}

\section{Patiëntenaanbod}

Het totaal aantal 'essentiële' ziektebeelden (37) dat studenten gedurende het co-schap zouden moeten tegenkomen ('eis'), en het aanbod (absoluut en als percentage van de eis) dat gedurende een co-schap van 4 weken kan worden verwacht (E) varieert op de 5 verschillende onderafdelingen. In tabel 3 is als illustratie weergegeven waar het patiëntenaanbod het grootst is (Algemene Interne I, 57\%) en waar het patiëntenaanbod het kleinst is (Oncologie: 13\%). Op de overige afdelingen is het aanbod: Interne Geneeskunde II (55\%); Nefrologie (47\%); Longziekten (41\%). Het aanbod van ziektebeelden dat verwacht kan worden op de 5 onderafdelingen varieert dus per onderafdeling, maar op de meeste onderafdelingen zijn uit elk cluster van ziektebeelden wel patiënten te verwachten.

Tabel 3. 'Essentiële' ziektebeelden: eis en verwachte waarde (E).

\begin{tabular}{lccccc}
\hline Clusters & Eis ${ }^{1}$ ) & $\begin{array}{c}\text { Interne Geneeskunde I } \\
\text { E }^{2} \text { percentage }\end{array}$ & $\begin{array}{c}\text { Oncologie } \\
\text { E }^{2} \text { percentage }\end{array}$ \\
\hline Ziekten van maag-darm kanaal & 4 & 3.0 & 75 & 1.0 & 25 \\
Hartziekten & 6 & 3.2 & 53 & 0.8 & 13 \\
Endocrinologische aandoeningen & 6 & 3.4 & 57 & 0.5 & 8 \\
Aandoeningen van longen/luchtwegen & 6 & 3.7 & 62 & 1.4 & 23 \\
Hematologische aandoeningen & 2 & 0.8 & 40 & 0.4 & 20 \\
Aandoeningen van lever, gal en pancreas & 4 & 2.6 & 65 & 0.2 & 5 \\
Circulatiestoornissen & 2 & 1.6 & 80 & 0.2 & 10 \\
Auto-immuun ziekten en ziekten & 2 & 0.8 & 40 & 0.0 & 0 \\
van het bewegingsapparaat & 3 & 2.0 & 67 & 0.2 & 7 \\
Nieraandoeningen & 2 & 0.2 & 10 & 0.0 & 0 \\
Infectieziekten & 37 & 21.3 & 57 & 4.7 & 13 \\
\hline Totaal & & & &
\end{tabular}

1) De eis is het aantal ziektebeelden dat volgens het Raamplan tijdens het co-schap op de afdeling Interne Geneeskunde aanwezig zou moeten zijn.

2) De verwachte waarde $(\mathrm{E})$ is het aantal ziektebeelden dat tijdens een co-schap van 4 weken op de afdeling Interne Geneeskunde verwacht mag worden. 
Het aantal 'optionele' ziektebeelden (65) dat studenten moeten tegenkomen tijdens hun co-schap ('eis') in relatie tot het verwachte aanbod (E) varieert per afdeling. Het verwachte aanbod op de onderafdeling Interne Geneeskunde I benadert voor een groot deel de eis (78\%); gevolgd door Interne Geneeskunde II (57\%), Nefrologie (41\%), Longziekten (34\%), en Oncologie (33\%). Uit nagenoeg alle clusters van ziektebeelden (ziekten van het maag-darmkanaal, hartziekten, endocrinologische aandoeningen, aandoeningen van longen/ luchtwegen/hematologische aandoeningen, aandoeningen van lever, gal en pancreas, circulatiestoornissen, auto-immuunziekten en ziekten van het bewegingsapparaat, nieraandoeningen, infectieziekten, verslavingen/vergiftigingen, vitamine deficiënties/intoxicaties, ziekten van de mamma) kan verwacht worden dat er patiënten op de afdeling liggen. Er zijn een paar afdelingen waar er geen patiënten zijn met ziekten van de mama (Interne Geneeskunde I), verslavingen/vergiftigingen (Nefrologie, Oncologie), endocrinologische aandoeningen (Longziekten), vitamine deficiënties (Oncologie).

\section{Gebruik patiëntenaanbod}

Er zijn lage overeenstemmingen gemeten tussen de arts en student: voor de complete set van ziektebeelden is de spreiding tussen .08 en .43; gemiddeld: .23. Voor de 'essentiële' ziektebeelden is de spreiding tussen .02 en 1.00; gemiddeld: .36. De sensitiviteit varieert: voor de complete set van ziektebeelden ligt de spreiding tussen .10 en .83; gemiddeld: .36. Voor de 'essentiële' ziektebeelden ligt de spreiding tussen .14 en 1.00; gemiddeld: .51. De specificiteit verschilt ook tussen de paren: voor de complete set van ziektebeelden is de spreiding tussen .85 en 1.00; gemiddeld:
.96. Voor de 'essentiële' ziektebeelden ligt de spreiding tussen .66 en 1.00; gemiddeld: .93 .

De overeenstemming tussen 4 paren van studenten is eveneens laag. Voor de complete set van ziektebeelden is de spreiding tussen .01 en .25; gemiddeld .13. Voor de 'essentiële' ziektebeelden ligt de spreiding tussen .03 en .42; gemiddeld: .23.

\section{Discussie}

In Groningen is een logboek ontwikkeld, ${ }^{10}$ waarmee de kwaliteit van de basisartsopleiding in termen van het Raamplan kan worden geëvalueerd. Door middel van dit logboek is inzicht verkregen in de omstandigheden (input) waaronder de eindtermen van het Raamplan met betrekking tot de ziektebeelden kunnen worden verworven. Door artsen het logboek te laten invullen is er vastgesteld dat er een groot en gevarieerd aanbod is aan patiënten op 5 onderafdelingen van de afdeling Interne Geneeskunde. De algemene onderafdelingen van de Interne Geneeskunde bieden wel een grotere variëteit aan ziektebeelden dan de specialistische onderafdelingen, maar als het co-schap een combinatie is van een algemene en specialistische afdeling dan kan de faculteit waarborgen dat studenten die ervaringen opdoen die zij volgens het Raamplan moeten opdoen. Vermeden moet worden dat studenten naar 2 specialistische afdelingen toe gaan. Door de logboekgegevens van artsen met die van studenten te vergelijken is ook vastgesteld dat studenten het onderwijsaanbod bestaande uit patiënten met ziektebeelden niet optimaal benutten. Bovendien blijken co-assistenten, die gedurende dezelfde periode op dezelfde afdeling werkzaam zijn, aanzienlijk te verschillen in hun leerervaringen met patiënten. Studenten maken fouten bij het invullen van 
het logboek. In de eerste plaats registreren ze niet alle ziektebeelden van patiënten die op de afdeling aanwezig zijn (vals negatieven); en in de tweede plaats schrijven zij ziektebeelden op die er niet zijn (vals positieven). Het aantal vals positieven is wel aanzienlijk minder in vergelijking met het aantal vals negatieven. Het verdient dus voorkeur om experts (artsen) het logboek te laten invullen, zoals in dit onderzoek is gedaan. Echter, dit is een kostbare manier om de kwaliteit van het onderwijs te evalueren. Niettemin is het aan te bevelen periodiek via artsen te weten te komen wat het patiëntenaabod is. Maar gestreefd moet worden naar betrouwbare data afkomstig van studenten, zodat de kwaliteit van het onderwijs ook door middel van hun gegevens kan worden geëvalueerd.

De kwaliteit van logboekgegevens van studenten moet niet alleen verbeterd worden om een goede evaluatie van het onderwijs mogelijk te maken, maar ook omdat het van belang is te evalueren wat de individuele student leert tijdens het coschap. Dit kan gedaan worden door studenten supervisie en feedback te geven zodat zij: (a) zich bewust worden van wat zij moeten leren; (b) gestimuleerd worden in de dingen die zij goed doen; (c) alert worden gemaakt op de hiaten in hun kennis en observatievermogen. Hier is een speciale rol gereserveerd voor de docent. Zowel assistenten als specialisten hebben een belangrijke bijdrage in de vorming van co-assistenten door hen te coachen op de werkvloer, en door een rolmodel te zijn. ${ }^{15-16}$ Omdat artsen over het algemeen geschoold zijn in de inhoud van wat zij onderwijzen, en niet in de wijze waarop zij onderwijzen, impliceert dit dat training en scholing van didactische vaardigheden wenselijk is.
Een ander aspect dat de kwaliteit van logboekgegevens van studenten zal vergroten, is de status die het logboek krijgt in het toetsreglement van de faculteit. Omdat examens 'het leren' sturen, ${ }^{17}$ zal de student datgene doen dat het examenprogramma voorschrijft. Als het logboek niet opgenomen is in het toetsreglement zal het ook niet door studenten worden ingevuld. Het opnemen van het logboek in het examenprogramma biedt mogelijkheden het te gebruiken als formatief of summatief evaluatie-middel voor de individuele student. Ook kan het logboek in het portfolio opgenomen worden als bewijs dat de student bepaalde ervaringen heeft opgedaan, en als bewijs voor de voortgang in zijn/haar persoonlijke en professionele ontwikkeling. 18

Concluderend: in dit onderzoek zijn de omstandigheden waaronder studenten leerervaringen opdoen met de ziektebeelden uit het Raamplan in kaart gebracht op de afdeling Interne Geneeskunde. Het logboek vormt een goed evaluatiemiddel om vast te stellen of: (a) de faculteit voldoende faciliteiten biedt (patiëntenaanbod), zodat studenten aan de gestelde eisen kunnen voldoen; en (b) studenten ervaringen opdoen met de vereiste ziektebeelden uit het Raamplan. Met het oog op de optimalisering van de onderwijsoutput en het bereiken van alle eisen uit het Raamplan is het van belang ook andere evaluatie-instrumenten te ontwikkelen om nader onderzoek te verrichten naar andere aspecten van de input van het onderwijs (bijvoorbeeld: de kwaliteit van de docenten, de gebruikte leermiddelen) alsook naar de wijze waarop studenten leren (bijvoorbeeld: het verwerven van patiënten ervaring met een logboek en zonder een logboek, het verwerven van leerstof tijdens onderwijssessie met tutor en zonder tutor). 


\section{Literatuur}

1. Deetman WJ. Eindtermen en deugdelijkheidseisen; kwaliteitsbewaking in het funderend onderwijs. In: Creemers BPM, Hoeben WThJG, Koops $\mathrm{K}$, ed. De kwaliteit van het onderwijs. Groningen: Wolters-Noordhoff; 1983:9-15.

2. Dolmans DHJM, Wolfhagen HAP. Interne kwaliteitszorg. In: Metz JCM, Scherpbier AJJA, Vleuten CPM van der, ed. Medisch onderwijs in de praktijk. Assen: Van Gorcum; 1995:301-8.

3. Vroeijenstijn AI. Externe kwaliteitszorg. In: Metz JCM, Scherpbier AJJA, Vleuten CPM van der, ed. Medisch onderwijs in de praktijk. Assen: Van Gorcum; 1995:309-14.

4. Coles C. How students learn: the process of learning. In: Jolly BJ, Rees L, ed. Medical education in the millennium. Oxford: Oxford University Press; 1998:61-81.

5. Bender W. Zelfstudie Faculteit der Medische Wetenschappen Opleiding Geneeskunde. Rijksuniversiteit Groningen; 1996.

6. Anoniem. De beste studies: gezondheid en natuur. Elsevier 2000:39-41.

7. Anoniem. Onderwijsvisitatie geneeskunde en gezondheidswetenschappen. Utrecht: VSNU; 1997.

8. Metz JCM, Stoelinga GBA, Pels Rijcken-van Erp Taalman Kip EH, Brand-Valkenburg BWM van den. Raamplan 1994 artsopleiding. Eindtermen van de artsopleiding. Nijmegen: Universitair publikatiebureau; 1994.

9. Anoniem. Besluit 'Opleidingseisen arts' ex wet BIG. Staatsblad van het Koninkrijk der Nederlanden. 's-Gravenhage; 1997:379.

10. Raghoebar-Krieger HMJ, Sleijfer DTh, Kreeftenberg HG, Hofstee WKB, Bender W. Objectives for an internship Internal Medicine: from the Dutch Blueprint (Raamplan 1994) to implementation into a practical logbook. Neth J Med 1999;55:168-76.

11. Rosenblatt RA, Gordon MJ, Phillips WR, Fletcher R. Reliability of student experience logs in clinical perceptorships. Family Medicine 1981;13:17-9.
12. Patricoski CT, Shannon K, Doyle GA. The accuracy of patient encounter logbooks used by family medicine clerkship students. Family Medicine 1998;30:487-9.

13. Bender W, Haagedoorn EML, Oldhoff J. Cancer education in Europe according to medical faculty and medical students. Groningen: WHO Collaborating Centre for Cancer Education; 1993.

14. Sneath PHA, Sokal RR. Numerical taxonomy: the principles and practice of numerical classification. San Francisco: W.H. Freeman and Company; 1973.

15. Kilminster SM, Jolly BC. Effective supervision in clinical practice settings: a literature review. Med Educ 2000;34:827-40.

16. Association of professors of Medicine. Preparing residents to become more effective teachers: a priority for Internal Medicine. Am J Med 2000;109:693-6.

17. Newble D, Jaeger K. The effect of assessments and examinations on the learning of medical students. Med Educ 1983;17:165-71.

18. Snadden D, Thomas M. The use of portfolio learning in medical education. Med Teach 1998;21: 192-9.

De auteurs:

Mw. dr. H.M.J. Raghoebar-Krieger, onderwijskundige

Dr. W. Bender, psycholoog

Dr. H.G. Kreeftenberg, internist

Prof. dr. D.Th. Sleijfer, internist-oncoloog

Allen zijn werkzaam bij de Faculteit der Medische Wetenschappen, Groningen.

\section{Correspondentieadres:}

Mw. dr. H.M.J. Raghoebar-Krieger, Faculteit der Medische Wetenschappen, Onderwijsinstituut, Antonius Deusinglaan 1, 9713 AV Groningen, tel: 050-3633105, fax: 050-3633865,h.m.j.raghoebar-krieger@med.rug.nl.

\section{Summary}

Quality control relates to the evaluation of what students have learned (the output). Because the output depends on factors as learning processes of students and input of education (lectures, teachers, patients et cetera), quality control also relates to the evaluation of these two aspects. In the Blueprint 1994 objectives (for instance diseases) for undergraduate medical education have been stated. The level of knowledge about these diseases can be assessed by examinations. However, the level of knowledge depends on possibilities for students to attain this knowledge in daily practice during contacts with patients with these diseases. Therefore, it is a requirement that these diseases are provided by the faculty. The general aim of this study is to describe this aspect of quality control of medical education by (1) determining whether patients with the required diseases are available (2) and by stating whether students make use of these available diseases. To answer these questions a logbook has been developed. Doctors and students (at the department of Internal Medicine) made records in their logbook about the diseases of patients which they encountered. The completed logbooks were analysed.

The logbook is a good evaluation instrument to describe the quality of medical education. Now, the quality of education can be described in terms of the Blueprint. It appeared that the availability of diseases is sufficient to meet the requirements of the Blueprint, when the clerkship takes place at a general as well as in a specialist-oriented subdivision. The learning potential provided by the available patients is not fully used by students. 